\title{
Life based on phosphite: a genome-guided analysis of Desulfotignum phosphitoxidans
}

\author{
Anja Poehlein ${ }^{1}$, Rolf Daniel', Bernhard Schink ${ }^{2}$ and Diliana D Simeonova ${ }^{2^{*}}$
}

\begin{abstract}
Background: The Delta-Proteobacterium Desulfotignum phosphitoxidans is a type strain of the genus Desulfotignum, which comprises to date only three species together with $D$. balticum and D. toluenicum. D. phosphitoxidans oxidizes phosphite to phosphate as its only source of electrons, with either sulfate or $\mathrm{CO}_{2}$ as electron acceptor to gain its metabolic energy, which is of exclusive interest. Sequencing of the genome of this bacterium was undertaken to elucidate the genomic basis of this so far unique type of energy metabolism.

Results: The genome contains 4,998,761 base pairs and 4646 genes of which 3609 were assigned to a function, and 1037 are without function prediction. Metabolic reconstruction revealed that most biosynthetic pathways of Gram negative, autotrophic sulfate reducers were present. Autotrophic $\mathrm{CO}_{2}$ assimilation proceeds through the Wood-Ljungdahl pathway. Additionally, we have found and confirmed the ability of the strain to couple phosphite oxidation to dissimilatory nitrate reduction to ammonia, which in itself is a new type of energy metabolism. Surprisingly, only two pathways for uptake, assimilation and utilization of inorganic and organic phosphonates were found in the genome. The unique for D. phosphitoxidans Ptx-Ptd cluster is involved in inorganic phosphite oxidation and an atypical C-P lyase-coding cluster (Phn) is involved in utilization of organophosphonates.

Conclusions: We present the whole genome sequence of the first bacterium able to gain metabolic energy via phosphite oxidation. The data obtained provide initial information on the composition and architecture of the phosphite-utilizing and energy-transducing systems needed to live with phosphite as an unusual electron donor.
\end{abstract}

Keywords: Desulfotignum phosphitoxidans, Dissimilatory anaerobic phosphite oxidation, Genome sequencing

\section{Background}

The phosphorus requirements of living cells are usually covered by phosphate and readily hydrolysable phosphate esters. In some cases as well as under phosphate starvation conditions, reduced organic and inorganic phosphorus compounds can be assimilated alternatively $[1,2]$. Several aerobic and anaerobic bacteria are able to oxidize hypophosphite (+I) and phosphite (+III) to phosphate $(+\mathrm{V})$, and to incorporate the latter into their biomass [3-9]. Phosphite can also be oxidized by P. stutzeri WM88 under denitrifying conditions when supplied as sole phosphorus source [7]. Whereas the phosphite oxidation pathways for assimilation purposes are well understood very little is known about the energetic side of this process. In addition to inorganic phosphonate

\footnotetext{
*Correspondence: Diliana.Simeonova@uni-konstanz.de

${ }^{2}$ Laboratory of Microbial Ecology, Department of Biology, University of

Konstanz, D-78457 Konstanz, Germany

Full list of author information is available at the end of the article
}

(phosphite), a wide range of organo phosphonates, compounds bearing stable carbon-phosphorus (C-P) bonds, are known to be oxidized and degraded aerobically as $\mathrm{P}$ - and/or C-sources [1,2,10-12].

Desulfotignum phosphitoxidans is a rod-shaped Gramnegative bacterium that is able to grow with phosphite as a single electron donor and $\mathrm{CO}_{2}$ as the only carbon source. It grows slowly, with a doubling time of 72 to $80 \mathrm{~h}$ and is able to oxidize phosphite, fumarate, pyruvate, glycine, glutamate, maleate and other substrates with concomitant reduction of sulfate to sulfide. The strain can grow as a homoacetogen by reducing $\mathrm{CO}_{2}$ to acetate. In addition the strain is unable to utilize ethanol or lactate as substrate, which is unusual for a SRB [13]. Phylogenetically, $D$. phosphitoxodans is a member of the Deltaproteobacteria, order Desulfobacterales, Desulfobacteriaceae family, and is the first and unique bacterium to date that is able to utilize phosphite as electron donor in its energy metabolism.

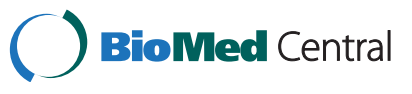

(c) 2013 Poehlein et al.; licensee BioMed Central Ltd. This is an open access article distributed under the terms of the Creative Commons Attribution License (http://creativecommons.org/licenses/by/2.0), which permits unrestricted use, distribution, and reproduction in any medium, provided the original work is properly cited. 
The oxidation of phosphite to phosphate with sulfate as electron acceptor results in $\Delta G^{\circ}=-364 \mathrm{~kJ}$ per mol sulfate, or $-91 \mathrm{~kJ}$ per mol phosphite. If $\mathrm{CO}_{2}$ is used as electron acceptor the Gibbs free energy of the reactions is $\Delta G^{\text {or }}=-308 \mathrm{~kJ}$ per mol acetate produced, or $-77 \mathrm{~kJ}$ per mol phosphite oxidized, as previously described [13]. These energy spans allow for ATP yields of 1 to $1.5 \mathrm{~mol}$ ATP per mol phosphite oxidized.

One major difference between previously described phosphite-assimilating bacteria and D. phosphitoxidans was found in the phosphite-oxidizing gene clusters, namely, the lack of an ABC-type phosphite uptake system and the presence of five new genes sharing no homology with any other gene known to participate in phosphite oxidation [14]. This finding together with the bacterium's ability to use phosphite as electron donor in its energy metabolism opens a new field for exploration of a highly specific microbial lifestyle. The genome sequence and reconstructed metabolic pathways of $D$. phosphitoxidans presented here provide the first glimpse on the genetic properties of this strain. This work shows as well that the bacterium possesses distinct systems to handle phosphorus compounds - as energy and as unique $\mathrm{P}$ sources, which distinguishes it from all other Bacteria.

\section{Methods}

\section{Media and growth conditions}

D. phosphitoxidans strain FiPS-3 (DSM 13687) was grown anaerobically under a $\mathrm{N}_{2} / \mathrm{CO}_{2}(90: 10$, v/v) headspace, at $30^{\circ} \mathrm{C}$ in mineral medium, supplemented with $10 \mathrm{mM}$ phosphite and $10 \mathrm{mM}$ sulfate [15], or with $10 \mathrm{mM}$ nitrate as the final electron acceptor. Multiple 1liter cultures were used to obtain cells for DNA extractions and scanning electron micrographs.

\section{Genome sequencing}

The genome sequencing strategy was described previously [16]. Briefly, D. phosphitoxidans genomic DNA was isolated with Purgene Core Kit B (Qiagen, Hilden, Germany) and MasterPure ${ }^{\mathrm{Tm}}$ complete DNA purification kit (Epicentre, Madison, USA). Plasmid extractions from 4 separate cultures in quadruplicate were performed with the plasmid purification kit QIAGEN (QIAGEN, Hilden, Germany), and digested in single reactions with the restriction endonucleases HindIII, PstI, NdeI and MfeI (Thermo Fisher Scientific, Fermentas $\mathrm{GmbH}$, Germany). The obtained fragments were separated on $1 \%$ agarose gels; the plasmid restriction map and its size were confirmed.

The extracted DNA was used in a combined sequencing approach using a 454 GS-FLX TitaniumXL system (Titanium GS70 chemistry, Roche Life Science, Mannheim, Germany) and the Genome Analyzer II (Illumina, San
Diego, CA, USA). Shotgun libraries resulted in $13.76 \times$ coverage from 176.236 reads for 454 shotgun sequencing and 102.45x coverage from 7.344.206 of 112 bp paired-end Illumina reads, respectively. The initial hybrid de novo assembly employing MIRA software resulted in 149 contigs. PCR-based techniques and Sanger sequencing $[17,18]$ together with the Gap4 (v.4.11) software were used to close the gaps. The software used for automatic gene predictions were YACOP and GLIMMER [19], while RNAmmer and tRNAscan were used for identification of rRNA and tRNA genes, respectively $[20,21]$. The functional annotation of the protein-coding genes was initially carried out with the IMG/ER (Intergrated Microbial Genomes/Expert Review) system [22] and manually curated by using the Swiss-Prot, TREMBL and InterPro databases [23].

The multiple sequence alignments were performed with ClustalW, with default settings [24].

\section{Electron microscopy}

Cells were harvested by filtration, through a $0.2 \mu \mathrm{m}$ PTFE filter and washed with $200 \mathrm{mM}$ Na-cacodylate buffer. Cells were fixed in $200 \mathrm{mM} \mathrm{Na}$-cacodylate buffer containing $180 \mathrm{mM}$ glucose, 6\% formaldehyde and 4\% glutaraldegyde and $30,50,70$ or $90 \%$ absolute ethanol on $5 \mathrm{~nm}$ thick gold-palladium grids.

\section{Results and discussion \\ General features}

The genome of $D$. phosphitoxidans contains one circular chromosome $(4,998,761 \mathrm{bp})$ and a small plasmid $(7,714 \mathrm{bp})$. The average $\mathrm{G}+\mathrm{C}$ content is $51.26 \%$. Of the 4699 putative genes identified, 4646 coded for proteins of which 3609 (76.69\%) were assigned to functions and 1037 (22.32\%) had no database match (Tables 1 and 2, Figure 1). The genome contains two gene copies for each 5S, 23S rRNA and 16S rRNA, and 47 tRNAs.

The phage identification was done by using the ProphageFinder tool [25] and subsequent manual annotation of the genes. Within the suggested region, only 1 prophage (Dpo_5c01030-Dpo_5c01350) in the genome of D. phosphitoxidans was identified. Typical genes coding for phage proteins such as integrase, portal protein, tail tape measure protein, several capsid proteins as well as a phage terminase are located in this region. Immediately upstream of this region, a gene coding for Cro/C1-type $\mathrm{HTH}$ DNA-binding domain-containing protein is located (Dpo_5c00890). This protein is often associated with prophage regions, but its function remains unclear.

With the help of the Semi-Automatic IS Annotation tool ISsaga [26] we could identify 120 transposable elements in the genome of D. phosphitoxidans, which were assigned to 20 different families. $48.25 \%$ of these genes can be allocated to unclassified IS families (ISNC), whereas the most abundant family within these group is 
Table 1 General features of the $D$. phosphitoxidans genome*

\begin{tabular}{lc}
\hline Category & Amount \\
\hline DNA contigs/scaffolds & 38 \\
DNA total number of bases & $4,998,761$ \\
$\quad$ Coding number of bases & $4,534,179$ \\
$\quad$ G+C content & $51.26 \%$ \\
ORFs ${ }^{\dagger}$, total & 4699 \\
$\quad$ RNA genes & $53(1.13 \%)$ \\
$\quad$ rRNA genes & $6(0.13 \%)$ \\
$\quad$ tRNA genes & $47(1.00 \%)$ \\
Protein coding genes & $4646(98.87 \%)$ \\
With assigned functions & $3609(76.80 \%)$ \\
Without function prediction & $1037(22.07 \%)$ \\
With COGs & $3648(77.63 \%)$ \\
With KOGs & $1430(30.43 \%)$ \\
With Pfam & $3810(81.80 \%)$ \\
With TIGRfam & $1373(29.22 \%)$ \\
In paralog clusters & $3524(74.99 \%)$ \\
\hline
\end{tabular}

*According to IMG database (https://img.jgi.doe.gov).

${ }^{\dagger} \mathrm{ORF} s$, Open reading frames, coding regions.

the ISNCY_ssgr_ISDol1 family where 42 transposable elements could be assigned to. More than $15 \%$ of the transposable elements found in the genome were classified as members of the ISL3 family and more than 7\% could be dedicated to the IS91 group. Transposable elements are often markers for genome plasticity and horizontal gene transfer, which are indicated by genomic islands (GI). These regions usually differ in $\mathrm{G}+\mathrm{C}$ content and Codon Adaptation Index (CAI) from the average of the genome $[27,28]$. By using the IslandPath-DIMOB software of the Islandviewer-platform we could identify 10 genomic islands with an overall size of $151 \mathrm{~kb}$ making up only $3 \%$ of the entire genome and their sizes range between $4 \mathrm{~kb}$ and $42 \mathrm{~kb}$. Most of the genes located within the genomic islands are coding for hypothetical proteins, transcriptional regulators, transposases and recombinases. In the largest genomic island (GI 9, Figure 2 [29]) 40 protein-encoding genes are located. Most of them are hypothetical, but an operon is coding for a complete type I restriction modification system (Dpo_8c00870Dpo_8c00890) is also present. During annotation and analysis of the $D$. phosphitoxidans genome we have identified five additional type I, two type II and two type III restriction modification systems. One genomic island (GI 1, Figure 2) is very interesting and extremely important for the metabolism of $D$. phosphitoxidans since the ptxEDptdFCGHI operon (Dpo_11c01210-Dpo_11c01260) coding the proteins involved in phosphite uptake and oxidation, as well as the transcriptional regulator that probably regulates this gene cluster, are located on it. We
Table 2 Functional distribution of orthologous protein groups of $D$. phosphitoxidans genome (COG classification)

\begin{tabular}{lcc}
\hline COG categories & $\begin{array}{c}\text { Gene } \\
\text { count }\end{array}$ & $\begin{array}{c}\% \text { of tota } \\
\text { (4699) }\end{array}$ \\
\hline
\end{tabular}

\section{Information storage and processing:}

Translation, ribosomal structure

and biogenesis

Transcription

DNA replication, recombination and repair

$171 \quad 3.63$

3.63

$222 \quad 4.72$

II. Cellular process:

$\begin{array}{lcc}\text { Cell cycle control and division, chromosome } & 48 & 1.02 \\ \text { partitioning } & & \\ \text { Posttranslational modification, protein } & 117 & 2.49 \\ \text { turnover, chaperones } & & \\ \text { Cell envelope biogenesis, outer membrane } & 256 & 5.45 \\ \text { Cell motility } & 56 & 1.19 \\ \text { Intracellular trafficking, secretion, vesicular } & 103 & 2.19 \\ \text { transport } & & \\ \text { Inorganic ion transport and metabolism } & 209 & 4.45 \\ \text { - Phosphorus metabolism (phosphate, } & 31 & \\ \text { phosphite and organophosphonates } & & \\ \text { - Sulphur and nitrogen } & 22 & \\ \text { - Other } & 156 & \\ \text { Signal transduction mechanisms } & 354 & 7.53 \\ \text { Defence mechanisms/Stress } & 78 & 1.66\end{array}$

III. Metabolism:

\begin{tabular}{lcc} 
Energy production and conversion & 424 & 9.02 \\
Carbohydrate transport and metabolism & 182 & 3.87 \\
$\begin{array}{l}\text { - Phosphorus - related (PTS system and sugar } \\
\text { phosphate permeases) }\end{array}$ & 14 & \\
Amino acid transport and metabolism & 332 & 7.06 \\
Nucleotide transport and metabolism & 66 & 1.41 \\
Coenzyme metabolism & 204 & 4.34 \\
Lipid metabolism & 127 & 2.70 \\
Secondary metabolites biosynthesis, transport & 84 & 1.79 \\
and catabolism & & \\
V. General function prediction only & 491 & 10.45 \\
Vnknown function & 309 & 6.58 \\
Vot in CoGs & 1051 & 22.37 \\
\hline
\end{tabular}

report on this feature in more details in a later chapter concerning the metabolism of inorganic reduced $\mathrm{P}$ compounds.

Two operons coding for Cas proteins involved in the prokaryotic CRISPR/cas defense system could be identified in the genome of $D$. phosphitoxidans. The first operon (Dpo_3c03500-Dpo_3c0350) consists of two metaldependent nucleases (Cas1 and Cas2) representing the universal cas genes, several genes code for proteins of the RAMP (Repeat-Associated Mysterious Proteins) superfamily (csm2-5, cas6) which are characteristic for type III 


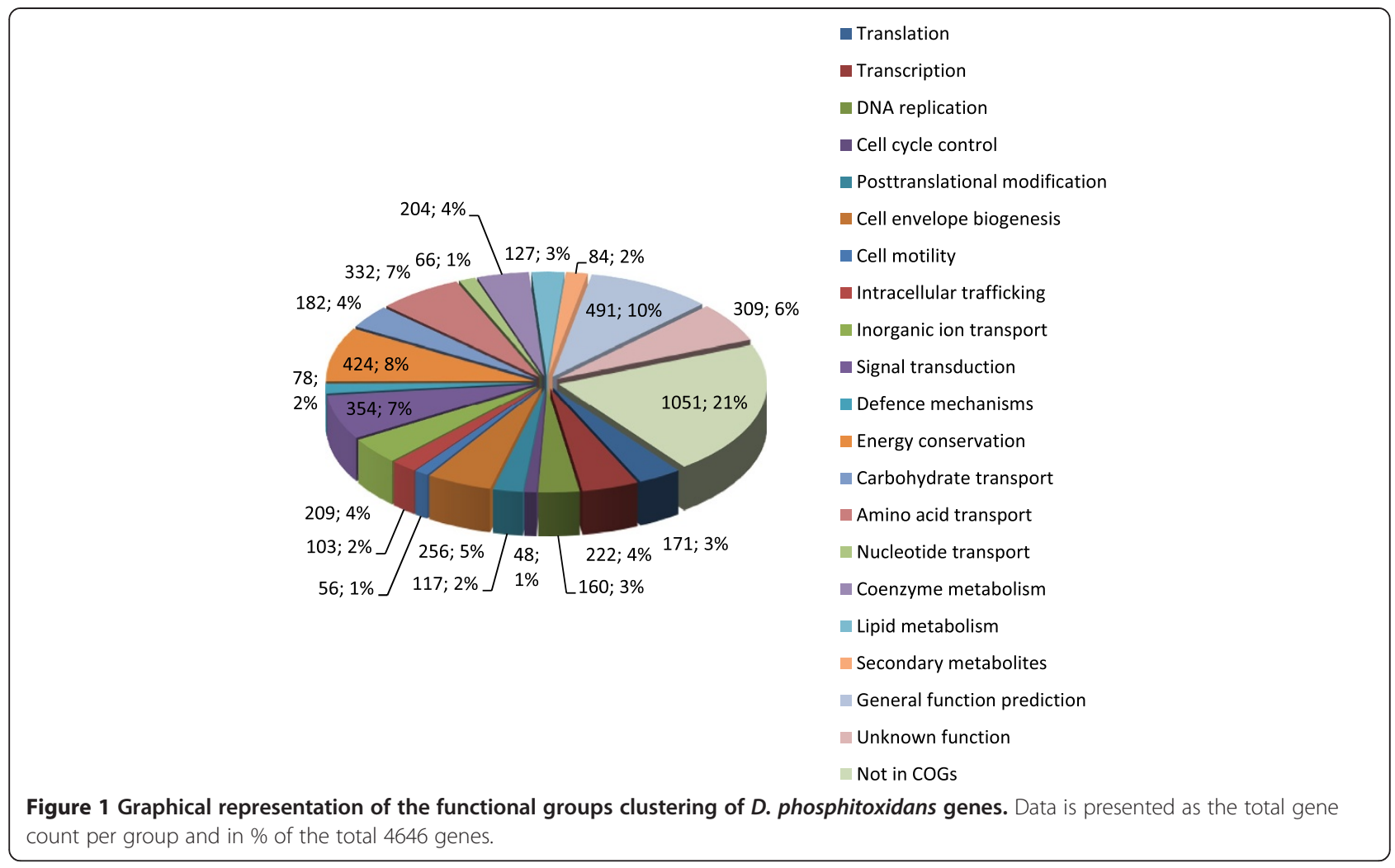

CRISPR-Cas systems. The presence of cas10 a gene coding for an HD-hydrolase allows further classification as the IIIA/MTUBE subtype. The second operon (Dpo_7c00020Dpo_7c00090) also consists of cas1 and cas2, in addition a gene coding for a RecB family exonuclease (cas4) and Cas5 and Cas7 are present in this operon. According to the polythetic classification this cluster can be allocated to the I-C/ DVULG subtype due to the presence of Cas3 and Cas8c the signature proteins for this subtype [30]. The presence of ten different restriction modification systems and two operons coding for a CRISPR/cas defense mechanism might be an explanation that there is only one prophage existing in the genome of $D$. phosphitoxidans.

\section{Comparison with other genomes}

The D. phosphitoxidans genome falls within the $90 \%$ of the most frequently occurring bacterial genome sizes in the range of 4.5 to $5.5 \mathrm{Mbp}$. When the 4646 protein coding ORFs of D. phosphitoxidans were compared pair-wise to other complete individual bacterial genomes, belonging to bacterial Phyla Firmicutes, Chlorobia, Spirochaetes and Proteobacteria, the best BLAST hits revealed closest associations to members of the Deltaproteobacteria, order Desulfobacterales, belonging to the family Desulfobacteraceae. The Desulfobacteraceae is a highly versatile family containing 23 distinct genera and more than 42 species, as shown on the List of prokaryotic names webpage (http://www.bacterio.net/classifgenerafamilies.html, search done on $30^{\text {th }}$ of July 2013). The highest numbers of best BLAST hits 3400 ORFs (73.18\%) and 2355 ORFs (50.68\%) were found against the genome of Desulfotignum balticum DSM 7044 and Desulfobacterium autotrophicum strain HRM2. However, the operon coding the phosphite oxidation ability in $D$. phosphitoxidans is unique for this strain and shows that it has been acquired through a lateral gene transfer from another yet unknown bacterium (Figure 2, circle 6). When compared to the genomes of $D$. balticum and $D$. autotrophicum, the genome of D. phosphitoxidans takes a middle place - it has one plasmid similar to D. autotrophicum, but the number of rRNA genes and the overall size of the genome is closest to those of $D$. balticum.

A comparison of the D. phosphitoxidans genome with the genomes of all sequenced organisms in the IMG database revealed that potential genes derived from Archaea or Eukaryotes were not present [31].

\section{Substrate tests and metabolic pathways constructions}

The information obtained from the sequenced genome on substrate degradation and different electron acceptors was confirmed through growth experiments and compared with previously published data $[13,14]$. In addition to prior known growth substrates, we observed growth with carbon monoxide and maleate. No growth was observed with benzoate or 4-hydroxybenzoate. For both degradation pathways only the gene encoding the 


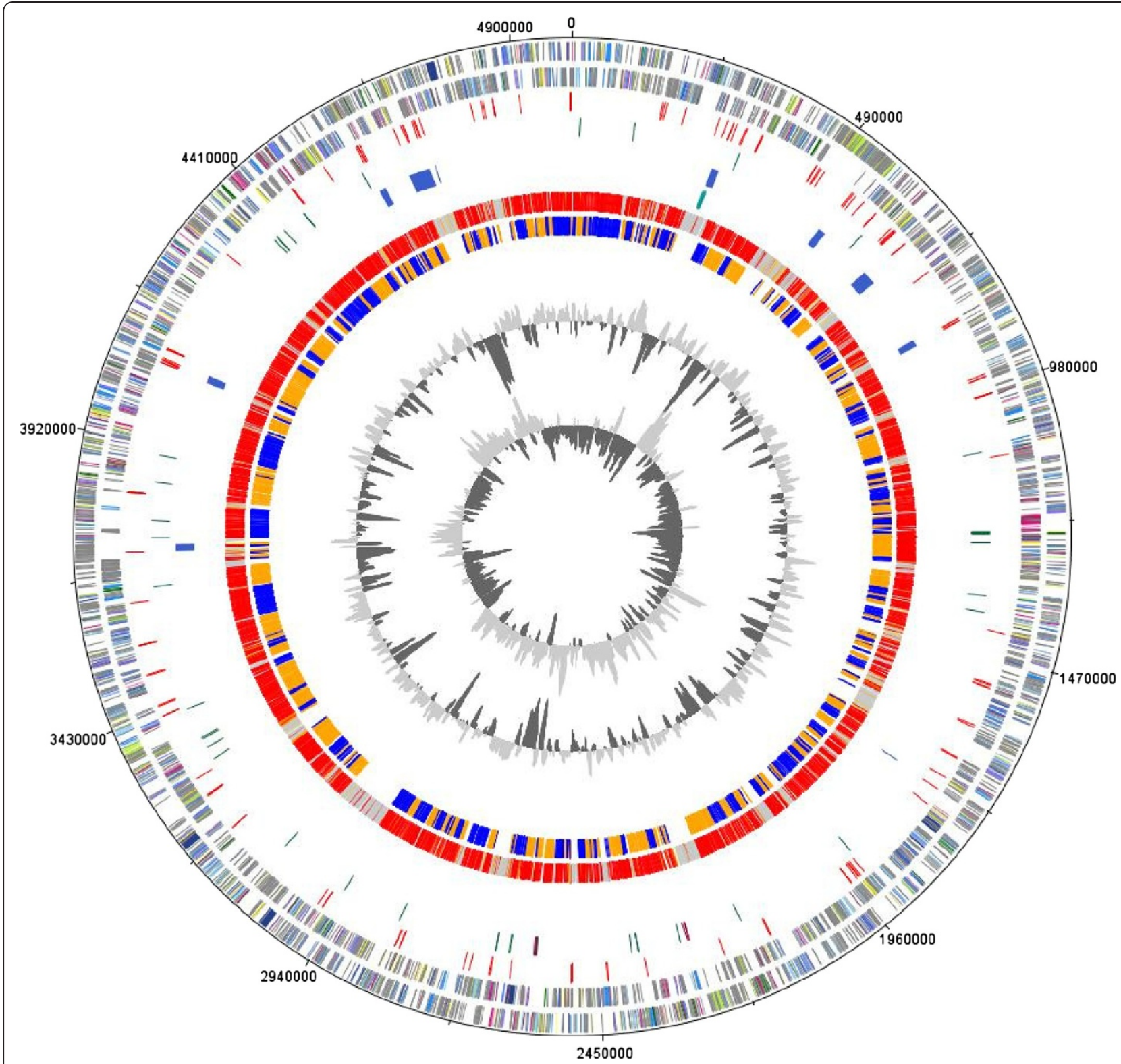

Figure 2 Comparison of the chromosome of $D$. phosphitoxidans with $D$. balticum visualized with DNAPlotter. From outside toward the centre of the figure: The red lines on the outer border show the gaps between the contigs. Genes encoded by the leading and the lagging strand are presented on circle 1 and 2, and marked in COG colours. Transposases (circle 3), rRNA-clusters and tRNAs (circle 4) are shown in red, pink and green. Genomic islands (circle 5) are shown in dark blue and were numbered clockwise, starting from 0. The ptxEDptdFCGHI operon is shown on circle 6 and marked in petroleum blue. A genome comparison based on bidirectional blasts were done against the genome of D. balticum (circle 7). The core genome is illustrated in red to light yellow and the pan genomes in grey with the following colour code: grey $>\mathrm{e}^{-20}-1$; light yellow $<\mathrm{e}^{-50}->\mathrm{e}^{-20}$; gold $<\mathrm{e}^{-50}->\mathrm{e}^{-90}$ light orange: $<\mathrm{e}^{-90}->\mathrm{e}^{-100}$ orange: $<\mathrm{e}^{-100}->\mathrm{e}^{-120}$ red: $<\mathrm{e}^{-120}-0$. The cluster analysis resulting from the bidirectional blasts is shown in circle 8. Both inner circles represent the $\mathrm{G}+\mathrm{C}$ content and the $\mathrm{G}+\mathrm{C}$ skew of the chromosome.

central enzyme 4-hydroxybenzoyl-CoA reductase (EC 1.3.7.9) is missing. Further, we found that the strain grows autotrophically with phosphite as electron donor and nitrate as electron acceptor.

\section{Central metabolism}

D. phosphitoxidans can grow heterotrophically with glucose, lactose, or galactose as carbon source. Hexoses are probably imported through a PTS-system (EC 2.7.1.69) to form glucose-6-phosphate; the further path leads via fructose-6-phosphate into glycolysis to form phosphoenolpyruvate and pyruvate. Surprisingly, the fructose-1,6bisphosphate aldolase (EC 4.1.2.13) is missing in the genome. The function of this enzyme could be replaced by reactions of the pentose phosphate cycle: Two subsequent transaldolase reactions could convert 
fructose-6-phosphate with erythrose-4-phosphate (EC 2.2.1.2, Dpo_2c03050) to glyceraldehyde-3-phosphate and sedoheptulose-7-phosphate which recycles erythrose4-phosphate with production of a further glyceraldehyde-3-phosphate through a transaldolase reaction. The pentose phosphate cycle is complete and could allow utilization of pentoses. Growth with arabinose and xylose has been documented before [13], but could not be reproduced in recent experiments. The incomplete glycolytic pathway could explain why growth of this bacterium with sugars is rather slow and poor. This is consistent with the fact that most sulfate-reducing bacteria do not use sugars at all.

For autotrophic growth, D. phosphitoxidans uses the carbon monoxide (CO) dehydrogenase (Wood-Ljungdahl) pathway for which all necessary enzymes were found in the genome (Figure 3). In addition, $\mathrm{CO}$ dehydrogenase activity had been documented previously [13]. This pathway is also used in lithotrophic growth with phosphite as electron donor and $\mathrm{CO}_{2}$ as sole electron acceptor, to form acetate as reduced reaction product through homoacetogenesis. All enzymes of the citric acid cycle are present, except for succinate dehydrogenase. Presence of fumarate reductase (menaquinone) instead indicates that the $\mathrm{C}_{4}$-dicarboxylic acid branch of the citric acid cycle is used in the reductive direction. Therefore the reactions of the citric acid cycle in this bacterium serve merely as a supply system for biosynthesis of amino acids and other important building blocks. Presence of genes encoding citrate synthase (EC 2.3.3.1, Dpo_14c00120, Dpo_20c00240) and absence of potential genes for ATP-citrate lyase (EC 2.3.3.8) indicates that the reductive citric acid cycle is not used for autotrophic $\mathrm{CO}_{2}$ assimilation in this bacterium. In addition putative genes encoding key enzymes of the glyoxylate shunt are missing.

In gluconeogenesis during autotrophic growth, pyruvate is formed reductively from acetyl-CoA through pyruvate synthase (EC 1.2.7.1, Dpo_10c00680 - Dpo_10c00700) and can be activated to phosphoenolpyruvate through pyruvate

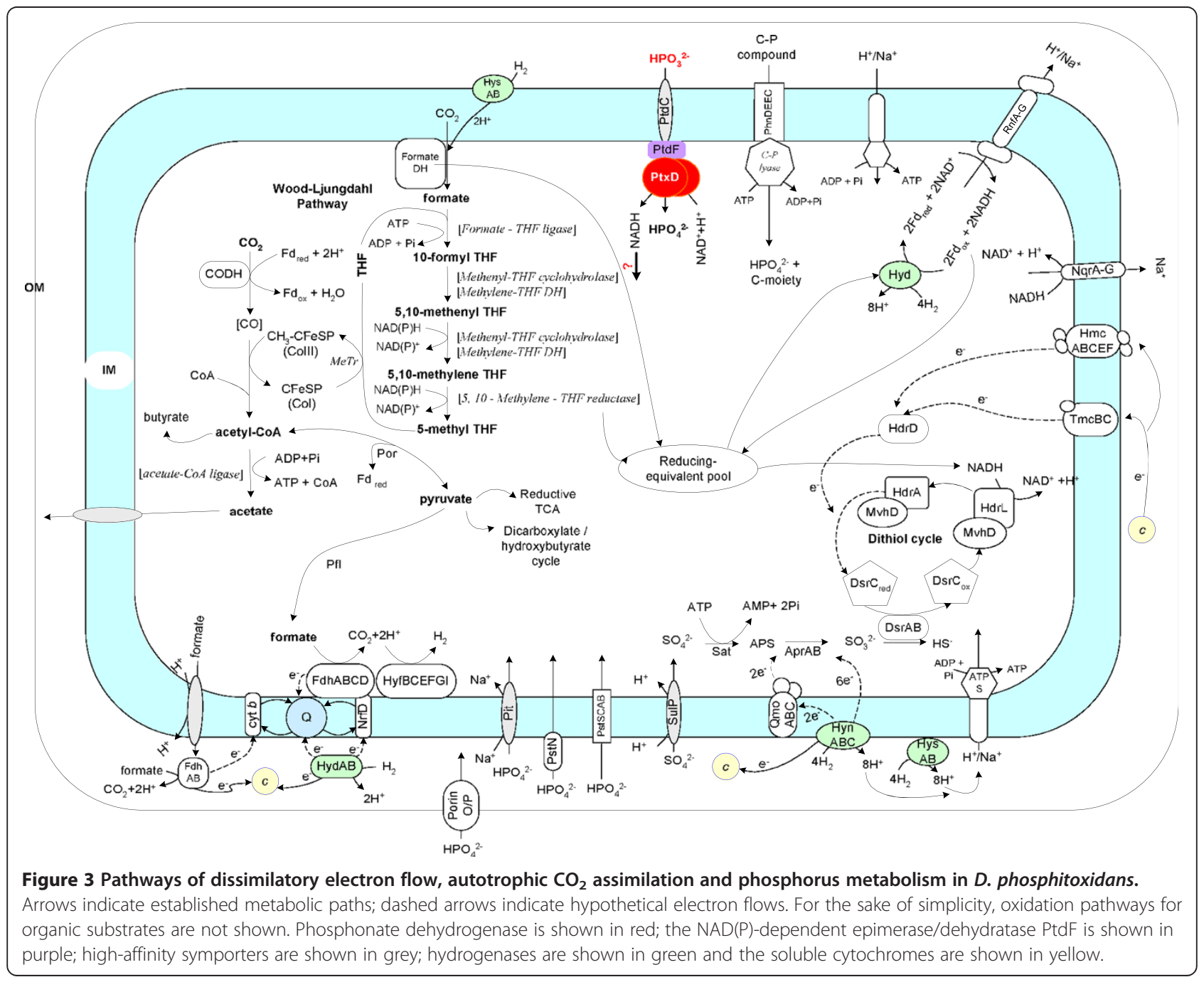


phosphate dikinase (EC 2.7.9.1, Dpo_5c02610; Dpo_ 6c01290) or pyruvate water dikinase (EC 2.7.9.2, Dpo_2c00560; Dpo_3c01990; Dpo_3c02000; Dpo_9c01030). Gluconeogenesis is driven by employing steps of the pentose phosphate cycle to produce hexose units for synthesis of cell wall polysaccharides. This synthesis starts from fructose-6-phosphate via glutamine: fructose-6-phosphate transaminase (EC 2.6.1.16, Dpo_2c00930) to glucosamine6-phosphate; all genes necessary for synthesis of peptidoglycan via acetylglucosamine and addition of the lactyl ether to the biosynthesis of the amino acid side branch were found to be present.

In the pathway for tetrahydrofolate biosynthesis, all required genes despite the dihydrofolate reductase gene were found in the genome, but a thymidylate synthase gene was identified which has been described in several other genomes as a bifunctional thymidylate synthase/ dihydrofolate reductase enzyme. The adenosylcobalamin (vitamin $\mathrm{B}_{12}$ ) biosynthesis pathway is almost complete, where all genes for synthesis of precorrin-3A were found. Of the two pathways for cobalt insertion, i.e., the "early" and the "late" cobalt insertion pathway, some enzymes are missing in either case. The "early" cobalt insertion lacks the precorrin-2 cobalt chelatase and the cobalt-precorrin-7 (C15)-methyltransferase genes, while the "late" one has no precorrin-3B synthase, precorrin$6 \mathrm{~B}$ synthase, and cobaltochelatase genes. These functions are covered by alternative enzymes [32].

Synthesis of coenzyme A is complete, as is the synthesis of ferredoxins for transfer of low-potential electrons, e.g., for reduction of $\mathrm{CO}_{2}$ to $\mathrm{CO}$.

\section{Metabolism of inorganic phosphate (Pi)}

The genome of $D$. phosphitoxidans contains the genes for both two-component signal transduction pathways of the Pho regulon, encoded by phoBR (Gram negative bacteria), and phoPR (Gram-positive bacteria), such as Clostridium acetobutylicum or Bacillus subtilis. This is another unique feature of the $D$. phosphitoxidans genome in comparison to other sulfate-reducing bacteria (SRB). Of 95 sequenced sulfate-reducers genomes available from IMG database, phoBR system was annotated in most of them, including D. balticum, D. autotrophicum HRM2, D. vulgaris vulgaris Hildenborough, whereas the phoPR system was coded in only 6 genomes including one Grampositive representative - Desulfosporosinus sp. Strain OT. Unexpectedly, we could not identify a gene coding for a periplasmic alkaline phosphatase $p h o A$ in the genome. It was shown in $E$. coli that this enzyme is involved in the utilization of phosphite as phosphorus source under phosphorus starvation [8] and plays also a major role in the supplementation of phosphorus during growth under phosphorus limitation and/or uptake of phosphate esters. PhoA is not present as well in the D. autotrophicum
HRM2 genome, but in most of SRB there is at least one copy of a periplasmic alkaline phosphatase gene. In the genome of the closest relative of $D$. phosphitoxidans, $D$. balticum, we found a gene product which belongs to the alkaline phosphatase superfamily but was not unequivocally annotated as an alkaline phosphatase. In addition, we could not identify unequivocally a phosphodiesterase (PhoD) gene ortholog, but nevertheless, several genes coding for phosphoric mono- and di-ester hydrolases and two copies (Dpo_7c02380; Dpo_1c03120) of the inorganic diphosphatase (Ppa) were present in the genome. The diphosphate phosphohydrolase is known to act on phosphoric acid anhydrides with a broad specificity that varies according to the source and the activating metal ion, thus being identical with the alkaline phosphatase (EC 3.1.3.1) or the glucose-6-phosphatase (EC 3.1.3.9) [33,34].

The phosphate requirements of $D$. phosphitoxidans can be covered via all three Pi uptake systems known [35]: i) a low affinity system (Pit); ii) a high affinity (Pst) system, and iii) a phosphate ester uptake system PTS (fructose and mannose specific). Although the strain grew with glucose, neither the genes encoding a Pi-linked antiport of glucose-6-P (UhpT, UgpA or UgpB), nor the GlpT protein of the antiport system for the transport of sn-glycerol-3-P were identified. Nevertheless, 7 genes of the PTS system (including ptsI Dpo_5c02530, ptsH Dpo_5c02520 and ptsN Dpo_3c02590) and 7 genes coding for sugar phosphate permeases were identified in the genome (Figure 3, Table 2), which is in agreement with a previously reported ability of the strain to grow slowly with C6 and C5 sugars [13]. The low-affinity (Pit) system is represented by two $\mathrm{Na}^{+} /$phosphate symporter genes (Dpo_7c01660; Dpo_4c03310) and one phosphateselective porin (Dpo_3c01140). A comparison between $D$. phosphotoxidans genome and the other SRB genomes shows that only D. autotrophicum HRM2 and D. toluolica Tol2 genomes contained one copy of Pit each. Surprisingly none of the publicly available SRB genomes contained a gene orthologous to the phosphate-selective porin found in D. phosphitoxidans. The Pi starvation-inducible high-affinity Pst system is represented in D. phosphitoxidans by only one complete set of genes organized in an operon structure (pstSCAB,phoL), whereas pstS, pst $A$ and pstB genes were found in multiple copies (Figure 3, Table 2). Also, this system is the most abundant one amongst SRB, where all strains sequenced to date possess it in at least one copy.

\section{Metabolism of organic reduced $\mathrm{P}$ compounds (organophosphonates)}

In addition to the Pi supplementation systems, D. phosphitoxidans is able to cover its phosphorus requirements via reduced organic phosphorus compounds. Of the four distinct organophosphonate degradation pathways identified 
so far, only the carbon-phosphorus lyase (phn) gene cluster was found in D. phosphitoxidans. The gene locus is split in two parts, phnGHIJKLM (the minimal region required for C-P bond cleavage, Dpo_1c08140 to Dpo_1c08080) and phnDEEC (phosphonic acid transporter region, Dpo_1c07910 to Dpo_1c07940), which are separated by 13 genes (Figure 4). It is shorter than the 14gene C-P lyase locus of E. coli and misses the PhnNP accessory proteins and the $\mathrm{PhnFO}$ assumed to be involved in the regulation of the cellular phosphorus level $[11,36]$. Nevertheless, D. phosphitoxidans utilizes alkylphosphonates (triethyl phosphite, diisopropyl phosphite), organophosphonates (2-aminoethyl phosphonate, tert-butylphosphonic acid) and phenylphosphonate as the only phosphorus source for growth, but not as carbon or energy source. This is in accordance with the previously shown broad substrate spectrum specificity of the C-P lyase pathway [12] in several Pseudomonads, Escherichia hermannii, Bacillus megaterium, Actinomyces spp. and the marine diazotroph Trichodesmium [10]. To compare, of 95 whole genome sequenced SRB in IMG data base, only 11 more contained a C-P lyase operon, excluding the closest relative Desulfotignum balticum DSM 7044 ( by August, $1^{\text {-st }}, 2013$ ). The C-P lyase operon was found in the genomes of both Gram (-) and Gram (+) SRB.

The pathways of 2-aminoethyl phosphonate degradation require the presence of either a phosphonatase that cleaves 2-phosphonoacetaldehyde to acetaldehyde and phosphate or the phosphonoacetaldehyde dehydrogenase coupled to phosphonoacetate hydrolase (PhnWYPhnA) pathways $[37,38]$. Strikingly, no gene homologous to phosphonatase (PhnX, EC 3.11.1.1) has been found in D. phosphitoxidans. This is in consistence with the other SRB genomes available to date. In addition we found that 18 out of the 95 SRB strains had a phnA coding for phosphonoacetate hydrolase. An interesting observation is that the PhnA was found only in Gram (-) SRB, but not in Gram (+). In conclusion, only three SRB species contained genes coding for both organophosphonates degradation pathways, the C-P lyase and the phosphonatase pathway: Desulfomicrobium baculatum $\times$ DSM 4028, Desulfobacter curvatus DSM 3379, and Desulfobacula toluolica Tol2.

\section{Inorganic reduced $\mathrm{P}$ compounds metabolism}

The strain's dual ability to utilize phosphite as a single phosphorus source and/or as an electron source to support its energy metabolism distinguishes it from all other phosphite oxidizers known to date. The gene cluster ptxEDptdFCGHI of D. phosphitoxidans is encoded on the chromosome. Already was shown before that the partial cluster $p t x D$-prdFCG conferred phosphite uptake and oxidation ability to D. balticum DSM 7044 as a host strain, but did not allow the use of phosphite as an electron donor for chemolithotrophic growth [14]. The ptxEDptdFCGHI operon forms a genomic island which is surrounded by two transposases. This suggests its lateral gene transferfrom another organism (Figure 2). The D. phosphitoxidans genome contained only one copy of a phosphonate dehydrogenase $(p t x D)$ and, in contrast to the previously described phosphite oxidation gene clusters, the uptake of phosphite is not an ATP-dependent process. Phosphite uptake in this strain proceeds via a high-affinity MFS protein PtdC (Figure 3 and Figure 5), suggesting that its primary role is to supply an electron donor for the energy metabolism. To date, only in two other SRB genomes a gene was annotated which presumably codes for a phosphonate dehydrogenase (PtxD), but there are no physiological proofs of phosphite oxidation ability in those strains (search performed on 02. August 2013). The two strains are Desulfovibrio putealis DSM 16056 and Thermodesulfovibrio thiophilus DSM 17215.

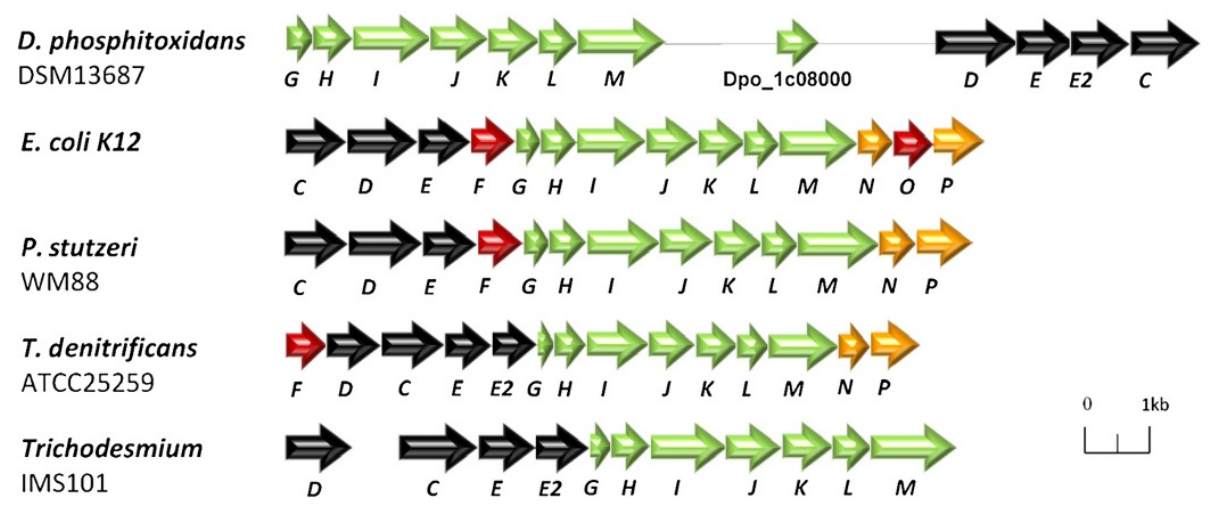

Figure 4 Comparison of the phn gene clusters of $D$. phosphitoxidans with other bacteria. The Phn (C-P lyase) complex allows the uptake and growth on a broad spectrum of organophosphonates. The genes involved in phosphonate transport are shown in black, C-P lyase catalytic subunits in green, regulation in red and the accessory genes in yellow. 


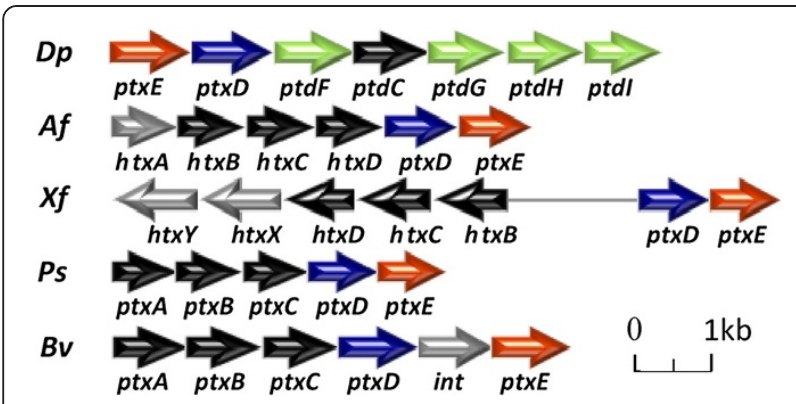

Figure 5 Operons involved in phosphite oxidation. D. phosphitoxidans (Dp), A. faecalis WM2072 (Af), X. flavus WM2814 $(X f)$, P. stutzeri WM88 (Ps) and B. vietnamiensis G4 (BV): regulatory genes (red), phosphite oxidation (blue), phosphite uptake (black). The specific genes for D. phosphitoxidans phosphite oxidation gene cluster, without homologs in the other species, are shown in green. The $h t x$ genes (grey) are involved in hypophosphite uptake and oxidation.

Further, no other genes known to be involved in the assimilation of reduced P-compounds as for example the $h t x$ locus which takes part in the uptake and oxidation of hypophosphite $(\mathrm{P}+\mathrm{I})$ to phosphate in P. stutzeri WM88 [39] were identified in the genome of D. phosphitoxidans. The same is true for all other sulfate-reducers.

\section{Sulfur metabolism}

As an obligate anaerobe and typical sulfate-reducer, $D$. phosphitoxidans is unable to use oxygen, but grows with sulfate, sulfite, thiosulfate, nitrate, $\mathrm{CO}_{2}$ or fumarate as electron acceptor. Sulfate reduction proceeds via ATP sulfurylase and APS reductase to sulfite, which is further reduced to $\mathrm{H}_{2} \mathrm{~S}$ by dissimilatory sulfite reductase DsrAB (Figure 3). The genome contains in addition one gene and one candidate gene for polysulfide reductase $\mathrm{NrfD}$ (Dpo_6c00850; Dpo_1c08450) that transfers electrons from the quinone pool, and for a thiosulfate reductase PhsAB (Dpo_3c03810; Dpo_3c03820). In addition, a quinone-coupled membrane-bound QmoABC complex is present in the genome, which presumably is involved in the direct transfer of electrons to the APS reductase (AprAB) as shown in Figure 3 [40]. Another complex related to the heterodisufide reductase and involved in menaquinol oxidation in sulfate reducers, HmeABCDE, described for the first time in Archaeoglobus fulgidus, is present as well in the genome of D. phosphitoxidans (Dpo_2c02400, Dpo_7c01170 to Dpo_7c01210) [41]. The same complex few years later was isolated and described in Desulfovibrio desulfuricans ATCC 27774 by another group, and was named DsrMKJOP [42,43]. Interesting point is that the subunits of this complex are coded in two different loci on the chromosome of $D$. phosphitoxidans, and apart from any other genes and complexes involved in sulfate reduction. This is an atypical constellation in comparison with the majority of the sulfate reducing organisms [43]. Two membrane-bound redox complexes, the $\mathrm{HmcABCDEF}$ having a function analogous to the Hme complex and a TmcABCD complex (a simplified version of the Hmc complex [44]), are present in a single copy each. The DsrC gene is present in two copies (Dpo_2c03440; Dpo_5c02880) and thus can form a functional unit with DsrAB.

\section{Nitrogen metabolism}

Nitrate is reduced to nitrite via a respiratory nitrate reductase type I NarGHI, complemented with a gene coding for NapC (Dpo_10c01280), the electron-transferring cytochrome $c$ subunit of the periplasmic nitrate reductase NapABCDE [45]. In addition, the genome contains a cytoplasmic nitrate reductase NasAB in a single copy. Nitrite is further reduced through a $\mathrm{NAD}(\mathrm{P})$-dependent dissimilatory nitrite reductase (EC 1.7.1.4, Dpo_11c00510) or a cytochrome c nitrite reductase (EC 1.7.2.2, Dpo_4c02890) to ammonia. A respiratory (NO-forming) nitrite reductase (EC 1.7.2.1) was not present, whereas the successive nitric oxide reductase NorB was (Dpo_19c00290). Further, nitric oxide reduction or nitrite reduction to ammonia can proceed as well through ammonia:ferricytochrome-c oxidoreductase (EC 1.7.2.2) which is known to act on $\mathrm{NO}$ and hydroxylamine as substrates [46]. Finally, the inspection of the genome reveals 6 genes sharing homology with the subunits of the ATP-hydrolysing dinitrogen oxidoreductase (EC 1.19.6.1). The ability of the strain to use nitrate as an electron acceptor was proven by growth tests with $10 \mathrm{mM}$ phosphite plus $15 \mathrm{mM}$ nitrate, in which a maximum of $2.25 \mathrm{mM} \mathrm{NH}_{3}$ was accumulated in the medium. This corresponds to the expected ammonia formation $(2.5 \mathrm{mM})$ if coupled stoichiometrically to the oxidation of $10 \mathrm{mM}$ phosphite.

\section{Energy conservation and electron flow}

The D. phosphitoxidans genome contains all genes necessary for the Wood-Ljungdahl pathway, which operates both in $\mathrm{CO}_{2}$ assimilation and energy metabolism (Figure 3). The genome lacks homologues of acetate kinase and phosphate acetyltransferase, although the latter activity $[47,48]$ but not acetate kinase activity was measured in cell-free extracts of cells grown autotrophically with phosphite. Moreover, four genes coding for putative acetyl/butyryl CoA transferases and three genes coding for acetyl-CoA synthetase (ADP-forming) were found; these enzymes are used by acetate-forming Archaea to synthesize ATP during acetate formation [49], and could take over the role of acetate kinase in D. phosphitoxidans.

Two soluble formate dehydrogenases, the FdhAB (Dpo_2c03450; Dpo_2c03460) and the NAD-dependent formate dehydrogenase I (EC 1.2.1.2) clusters, are present in the genome. Both enzyme activities were measured in 
extracts of autotrophically grown cells [50,51]. In addition to the aforementioned formate dehydrogenases, a membrane-associated FdhABD formate dehydrogenase was found. These findings suggest energy conservation by a formate cycle, as shown in Figure 3.

Amongst all 95 genomes of sulfate-reducing bacteria, only three contain NuoEFG genes from the 14-subunits NADH:ubiquinone oxidoreductase complex. The Desulfovibrio magneticus RS-1 and Syntrophobacter fumaroxidans MPOB harbour the entire NuoABCDEFGHIJKLMN cluster $[42,52]$, whereas $D$. phosphitoxidans contains only the EFG subunits. The genome of $D$. phosphitoxidans differs in the number of copies as well - four copies of the NuoEFG subunits forming the NADH dehydrogenase module of the NADH: ubiquinone reductase $\left(\mathrm{H}^{+}\right.$-translocating) complex (EC 1.6.5.3), but no further nuo genes [44]. In D. phosphitoxidans genome, the NuoEFG subunits are organized in putative transcriptional units together with a $\mathrm{CoB}-\mathrm{CoM}$ heterodisulfide reductase subunit $\mathrm{HdrA}$, a methyl-viologen-reducing hydrogenase MvhD (nuoEF GmvhD; nuoGEFmvhDhdrA), formate DH (nuoEFfdhF), and electron transfer flavoproteins EtfAB ( $h d r A m v h D$ $n u o E F G d f h D e t f A B)$. This indicates that the NADH generated during phosphite oxidation can be the actual electron donor for intracellular reduction of ferredoxin.

The genome of $D$. phosphitoxidans contains a soluble succinate dehydrogenase,encoded in a single copy by frdABC (Dpo_4c03460 to Dpo_4c03480), and a candidate gene for FrdD transmembrane subunit (Dpo_4c03580) between a fumarase FumA subunit and the succinate-CoA ligase (ADP-forming) gene cluster. The lack of complex II activity was proven by enzyme assays in cell extracts [53].

Unexpected for a strict anaerobe, the genome contains as well a gene coding for the $\mathrm{CyoE}$ subunit of the terminal cytochrome bo oxidase complex and homologs of the $\mathrm{CydAB}$, the terminal cytochrome $b d$ quinol oxidase subunits (Dpo_2c00830; Dpo_2c00840). Furthermore, four putative genes encoding subunits of the complex IV, cytochrome $c$ oxidase (EC 1.9.3.1) were found (Dpo_12c00840 to Dpo_12c00870). Their presence might be related to an enhanced resistance towards nitrite rather than to aerobic respiration [54,55]. The bacterial $\mathrm{F}_{0} \mathrm{~F}_{1}$-type ATPase is present in two complete copies (Dpo_2c00210 to Dpo_2c00290), one of which is split into two clusters, one coding for the $F_{1}$ unit (containing the $\alpha \beta \gamma \delta \varepsilon$ subunits) and another one coding for the $\mathrm{F}_{0}$ unit ( $a b c$-subunits). Surprisingly, an alignment of the two gamma subunits revealed closest relation to the $\mathrm{Na}^{+}$-dependent ATPases, rather than to the $\mathrm{H}^{+}$ dependent ones, as shown on Figure 6.

The electron flow during phosphite oxidation is still unknown, but the genome of $D$. phosphitoxidans reveals several options for respiratory electron transport through $\mathrm{FMNH}_{2^{-}}, \mathrm{FADH}_{2^{-}}$and $\mathrm{NAD}(\mathrm{P}) \mathrm{H}$-linked reactions. Within the genome, the highest number of genes assigned to function (424 genes) is related to the energy conversion COG category, with exception of the general-functionprediction COG group (491 genes; Table 2, Figure 1). The number of $b$-type cytochromes in the genome is limited to three genes (Dpo_7c01210; Dpo_2c00850; Dpo_ 19c00130). Substantially higher is the number of putative $c$-type cytochromes - 20, including one tetra-heme cytochrome $c_{3}$, three genes for cytochrome $c_{552}$, and one for cytochrome $c_{554}$. Furthermore, two putative genes for electron transport proteins, seven gene clusters etf $A B$ (electron transport flavoproteins), and ten flavoproteins seven of which are flavodoxins were found in the genome. Fourteen Fe-S, two $2 \mathrm{Fe}-2 \mathrm{~S}$ and 29 genes coding for $4 \mathrm{Fe}-$ $4 \mathrm{~S}$-containing proteins indicate an electron transfer that couples substrate metabolism with redox carriers such as ferredoxins and/or $\operatorname{NAD}(\mathrm{P})^{+}$in the cytoplasm of the cell. The soluble electron transfer machinery of the strain consists of a [NiFeSe]-periplasmic hydrogenase HysAB, a [NiFe]-membrane bound periplasmic hydrogenase HynCAB (EC 1.12.99.6), a HypABEDFC hydrogenase, and a soluble periplasmic [NiFe]-hydrogen: quinone oxidoreductase

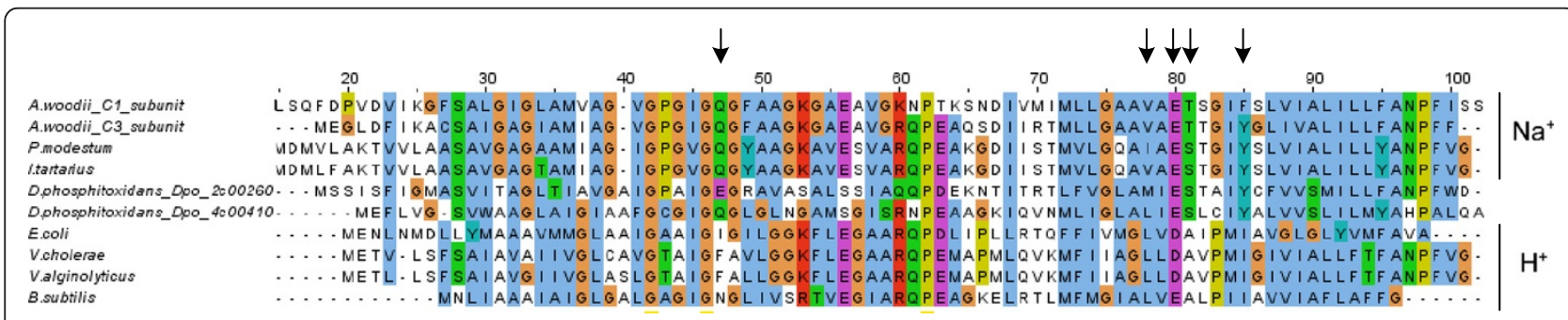

Figure 6 Comparison of the $D$. phosphitoxidans' two gamma subunits of the $\mathrm{F}_{1} \mathrm{~F}_{0}$ ATPases with the gamma subunits of $\mathrm{Na}^{+}$, and $\mathbf{H}^{+}$-translocating ATPases. NCBI protein database accession numbers used: Escherichia coli (P68699), Vibrio cholerae (AAF95908), Vibrio alginolyticus (POA308), Bacillus subtilis (P37815), Acetobacterium woodii, C1 subunit (AFA47025.1) and C3 subunit (AFA47026.1), Propionigenium modestum (P21905), Ilyobacter tartaricus (Q8KRV3), D. phosphitoxidans (Dpo_2c00260), and (Dpo_4c00410). Arrow marks show the positions of the conserved amino acids for sodium ion binding. D. phosphitoxidans gamma subunit Dpo_2c00260 shows a non-conserved substitution at position 47 (glutamic acid instead of a glutamine), and a substitution at position 78 (methionine), whereas the Dpo_4c00410, differs in one amino acid, at position 78 (leucine), which is conserved amongst $\mathrm{H}^{+}$-translocating ATPases. 
HydAB (EC 1.12.5.1). In addition, we found a six-gene cluster homologous to the ten-subunit Hyf complex encoding a membrane-associated $\mathrm{H}_{2}$-evolving respiratory [NiFe]-hydrogenase originally described for E. coli [56]. The genome contains a set of five genes homologous to the CoB-CoM heterodisulfide reductase (HdrABCDE) and ten copies of the MvhD methyl-viologen reducing hydrogenase. Together with the presence of several periplasmic hydrogenases, the HmcABCDEF and the TmcACBD complexes known to be involved in electron transfer from the periplasm to the cytoplasm during $\mathrm{H}_{2}$ oxidation [57], these findings indicate the ability of $D$. phosphitoxidans to use hydrogen in addition to formate as electron donor.

\section{Ion translocation and ATP synthesis}

In the genome of $D$. phosphitoxidans a set of six genes (Dpo_1c03590 - Dpo_1c03640) was found of which five were identified as $r n f C D G E A$, those are coding subunits of the Rnf ion translocation system found in Rhodobacter capsulatus, Clostridium tetani, Bacteroides vulgatus and others [58-62] (Figure 7). The remaining gene (Dpo_1c03590) is a potential candidate to also belong to the Rnf complex, as it is a putative cytochrome $c$, containing a Fe-S center. The RnfABCDGEH complex of $R$. capsulatus is involved in electron transport to nitrogenase, driving the reversed electron transport from $\mathrm{NADH}$ to ferredoxin [59], whereas the gene clusters in Clostridia and Bacteroides vulgatus are believed to function in the generation of transmembrane ion gradients [58]. The presence of an Rnf-type complex in the genome of $D$. phosphitoxidans indicates that it might be involved in electron transport and energy conservation during phosphite oxidation. Our search in the IMG database against the $\mathrm{RnfC}, \mathrm{RnfD}$ and RnfE subunits revealed 36, 19, and 11 SRB strains, which harboured them, respectively. However, only 9 SRB genomes contained an Rnf complex belonging to two of the four
Rnf-complex types, shown in Figure 7. D. autotrophicum HRM2, D. phosphitoxidans and Desulfotomaculum kuznetzovii formed the type four Rnf complex in Figure 7A, presented in details in Figure 7B; Db. postgatei 2ac9, D. toluolica Tol2, Desulfomonile tjedjei DCB-1 DSM 6799, Desulfosarcina sp BuS5, Desulfobacter curvatus DSM 3379 and Desulfovibrio aminophilus DSM 12254 belong to the type two, and identical to the C. tetani Rnf complex, as shown in Figure 7A.

In addition to the Rnf complex, a $\mathrm{Na}^{+}$-dependent NADH:ubiquinone oxidoreductase NqrABCDEF complex was identified (Dpo_16c00300 to Dpo_16c00350), which is known to be typical of the respiratory chains of various marine and halophilic bacteria. Interestingly only 9 SRB genomes contained loci coding an Nqr complex, two of which are freshwater isolates - Syntrophobacter fumaroxidans MPOB and Desulfococcus oleovorans HxD3. The Nqr complex of D. phosphitoxidans is identical with the one found in Vibrio alginolyticus, Vibrio cholerae, and other marine and Gram-negative pathogens [63]. The primary function of this complex is the oxidation of NADH coupled to $\mathrm{Na}^{+}$ion transport across the cytoplasmic membrane [60]. Surprisingly D. balticum, being the closest relative of $D$. phosphitoxidans and a marine bacterium, does not harbour either an Rnf, or an Nqr complex, although there are genes annotated as subunits of these complexes, below the trusted cut-off.

\section{Stress}

The genome of $D$. phosphitoxidans contains genes for oxidative stress protection including one catalaseperoxidase (EC 1.11.1.21), three peroxiredoxins, six thioredoxins, one $\mathrm{Fe}$ - and one $\mathrm{Ni}$ - containing superoxide dismutase. This is in consistence with the other genomesequenced SRB, 22 of them have as well a catalaseperoxidase gene. Seventy-five have at least one gene copy for peroxiredoxin and 61 of them harbour a superoxide
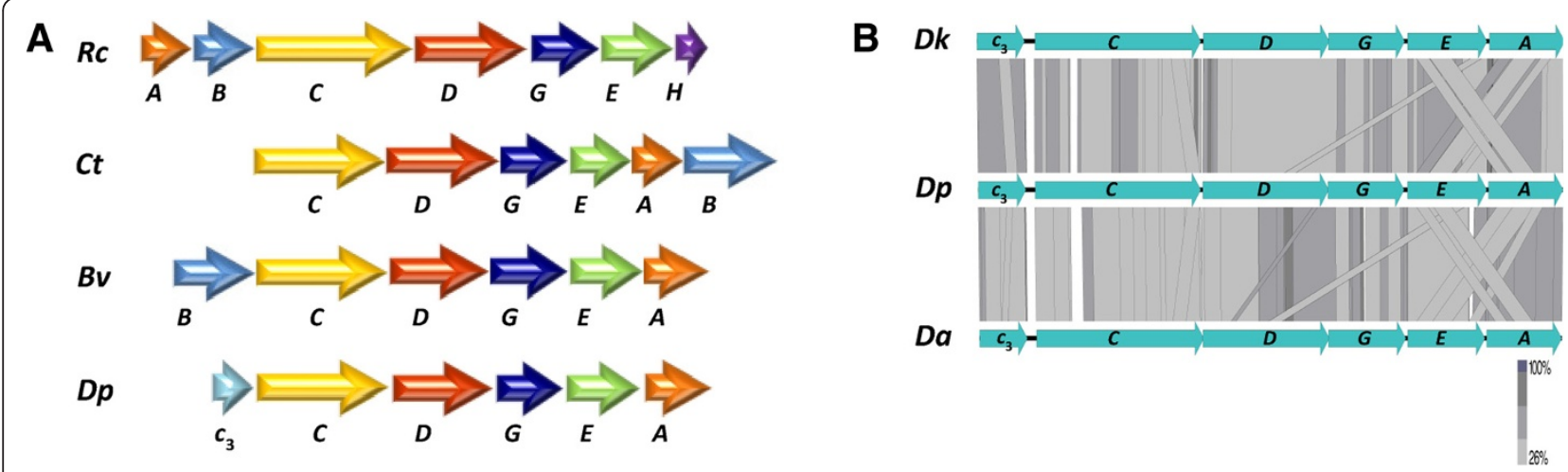

Figure 7 Rnf clusters comparisons. A) the rnf-type gene cluster in D. phosphitoxidans (Dp) and the rnf clusters of R. capsulatus (RC), C. tetani (Ct) and B. vulgatus (Bv). Genes are aligned 5' to 3' and the identically colored genes are homologous. B) A tBlastx comparison of Rnf clusters from Desulfotomaculum kuznetzovii (Dk), D. phosphitoxidans (Dp) and Desulfobacterium autotrophicum HRM2 (Da). The graphical presentation was generated with Easyfig software, and a cut-off value of 1e-10 was used. 
dismutase gene (EC 1.15.1.1) as D. phosphitoxidans does. Surprisingly, only D. phosphitoxidans and D. autotrophicum had PrxU coding genes for selenocystein-containing peroxiredoxin. In addition, two genes of the superoxide reductase system (desulfoferrodoxin) as found in obligate anaerobes were identified in the genome of D. phosphitoxidans.

Several genes coding for efflux pumps have been identified that confer resistance against heavy metals and metalloids, including the arsenite efflux pump (ACR3). Both TolC-dependent multidrug resistance systems were found in the genome: the $\mathrm{ABC}$-type, the MtdABC-TolC type and the AcrAB-TolC type, including some small RNDtype multidrug resistance proteins and a macrolidebinding efflux protein. Similarly only $30 \%$ (or 28) of all SRB with sequenced genomes contained a Type I secretion outer membrane protein TolC including D. balticum.

Genes for heat/cold-shock proteins include five chaperones, dnaK, dnaJ, grpE, a small heat-shock protein Hsp20, and an Hsp70 protein, as well as two cold-shock proteins. Also 16 genes are present encoding the universal stress protein UspA, two solvent and several acid-stress response proteins.

\section{Regulation and signal transduction}

The core polymerase (RpoA, RpoB, RpoC, RpoZ) along with four sigma factors $\sigma_{-}{ }^{70}$ (RpoD), $\sigma_{-}{ }^{54}$ (RpoN), $\sigma_{-}{ }^{32}$ $(\mathrm{RpoH})$ and $\sigma_{-}{ }^{24}(\mathrm{RpoE})$ confer promoter specificity in the genome of $D$. phosphitoxidans. Strikingly, no gene coding for stationary phase sigma factor $\sigma_{-}^{38}(\mathrm{RpoS})$ or a flagella biosynthesis sigma $\sigma_{-}{ }^{28}$ (FliA) were found. The genome of $D$. phosphitoxidans contains twenty-one $\sigma_{-}{ }^{54}$ dependent transcriptional regulators, seventeen $\mathrm{HTH}-$ type transcriptional regulators and eighty-five response regulators out of 354 genes involved in signal transduction mechanisms. Thus, this functional group is the second biggest COG group identified with $8.86 \%$ in the entire genome (Table 2).

\section{Motility and taxis}

D. phosphitoxidans is a non-motile bacterium sensu stricto that lacks flagellar structural proteins, $\sigma 28$ and anti- $\sigma 28$ factor (FlgM). Also the E. coli-type master switch proteins FlhCD are absent (Figure 8). Instead, the bacterium appears to be motile via gas vesicles, for which one gene was unequivocally identified in the genome (Dpo_1c07060). In addition six methyl-accepting chemotaxis proteins and three methylases for methylaccepting chemotaxis proteins were identified. Ten out of eleven MCP sensory proteins are involved in as yet unknown attractants and/or repellents for signal transduction via one CheA (Dpo_12c00440), two CheW (Dpo_1c03230, Dpo_12c00460) and two CheY-like proteins (Dpo_2c03950, Dpo_5c00010). Quorum signalling

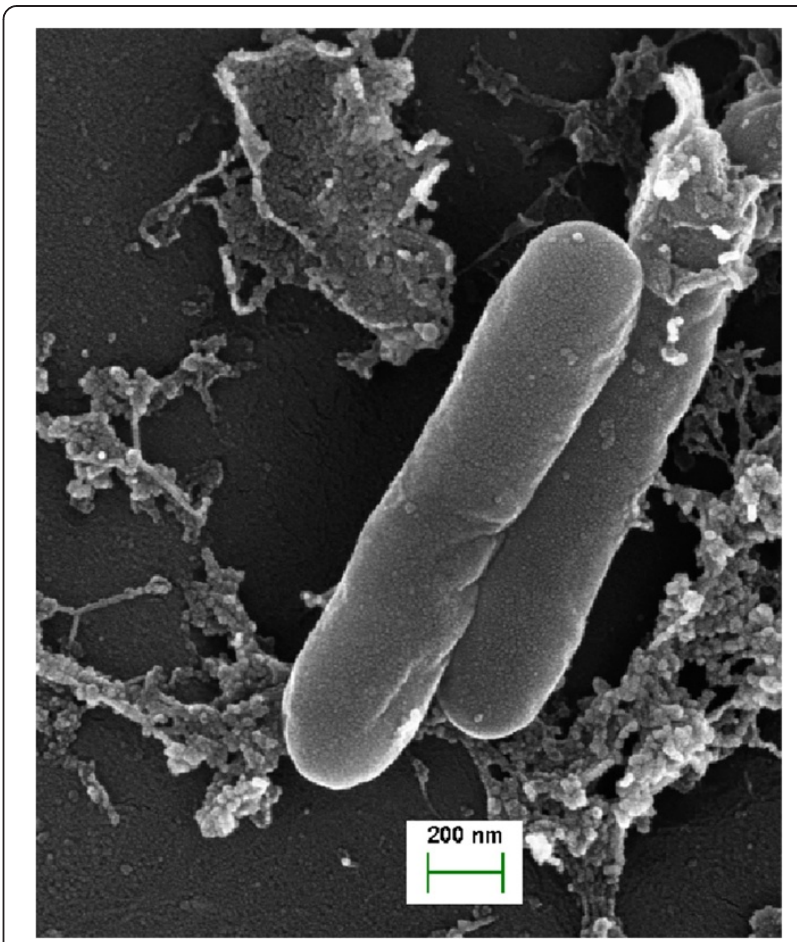

Figure 8 Scanning electron micrograph of $D$. phosphitoxidans cells in the mid-exponential growth-phase.

genes luxOQ (Dpo_1c07250, Dpo_10c00270) were specific only for $D$. phosphitoxidans in comparison to the 95 SRB genomes. D. balticum harbours only a luxQ. In addition, the D. phosphitoxidans genome contains the full set of conserved subunit genes involved in the synthesis of Type IV pili (pilBCDQ), except for the pilA.

\section{Conclusions}

The whole genome sequence of $D$. phosphitoxidans has provided an opportunity to understand the nature of phosphite oxidation and thereby derived energy as a unique feature of this bacterium amongst all known bacterial species.

The ptxEDptdFCGHI locus involved in phosphite oxidation is a genomic island on the chromosome of the strain, flanked downstream by a putative transposase belonging to the resolvase/recombinase family and upstream with a rolling-cycle transposase. Also, this clearly indicates that the locus was subject to a lateral gene transfer from another organism, which suggests that this type of metabolism might have a broader distribution in different environments and subsequently an impact on the phosphorus cycle in nature.

Further, the presence of NuoEFG coding genes, forming the NADH dehydrogenase module of the $\mathrm{NADH}$ : ubiquinone reductase $\left(\mathrm{H}^{+}\right.$-translocating) complex is as well unique for the genome of $D$. phosphitoxidans amongst all Gram (-) sulfate-reducing bacteria, and we 
expect that it plays a role in the energy conserving system.

Since phosphite can play an important role in the energetic metabolism of this bacterium, the strain has acquired additional both phosphorus two-component regulation systems - the PhoBR and PhoPR.

Finally, the narrow range of substrates that can serve as electron donors for this strain, its inability to grow via fermentation, and the surprisingly poor phosphonate uptake and utilization abilities, combined with the unique phosphite oxidation and energy conservation system of this strain, clearly underlines a highly specific and unique live strategy.

\section{Competing interests}

The corresponding author declares that there are no competing interests.

\section{Authors' contributions}

AP did the genome sequencing, DDS and AP did the genome annotations, DDS provided the experimental data, DDS and AP prepared the figures, and $\mathrm{DDS}, \mathrm{BS}, \mathrm{AP}$, and RD wrote the manuscript. All authors read and approved the final manuscript.

\section{Acknowledgments}

We thank Dr. Joachim Hentschel for taking electron micrographs of the strain, Antje Wiese and Kathleen Gollnow for technical assistance. This work was supported by a grant of the Deutsche Forschungsgemeinschaft, Bonn - Bad Godesberg GZ: SI 1300/4-1 (to D.D.S.).

\section{Author details}

'Genomic and Applied Microbiology and Göttingen Genomics Laboratory, Georg-August University Göttingen, D-37077 Göttingen, Germany. ${ }^{2}$ Laboratory of Microbial Ecology, Department of Biology, University of Konstanz, D-78457 Konstanz, Germany.

Received: 26 April 2013 Accepted: 30 October 2013

Published: 2 November 2013

\section{References}

1. Kokonova SV, Nesmeyanova MA: Phosphonates and their degradation by microorganisms. Biochemistry (Moscow) 2002, 67(2):184-195.

2. White AK, Metcalf WW: Microbial metabolism of reduced phosphorus compounds. Annu Rev Microbiol 2007, 61:379-400.

3. Casida LE Jr: Microbial oxidation and utilization of orthophosphite during growth. J Bacterio/ 1960, 80(2):237-241.

4. Foster TL, Winans $L \mathrm{Jr}$, Helms SJ: Anaerobic utilization of phosphite and hypophosphite by Bacillus sp. Appl Environ Microbiol 1978, 35(5):937-944.

5. Malacinski G, Konetzka WA: Orthophosphite-nicotinamide adenine dinucleotide oxidoreductase from Pseudomonas fluorescens. J Bacteriol 1966, 93(2):578-582.

6. Metcalf WW, Wanner BL: Involvement of the Escherichia coli phn (psiD) gene cluster in assimilation of phosphorus in the form of phosphonates, phosphite, Pi esters, and Pi. J Bacteriol 1991, 173(2):587-600.

7. Metcalf WW, Wolfe RS: Molecular genetic analysis of phosphite and hypophosphite oxidation by Pseudomonas stutzeri WM88. J Bacteriol 1998, 180(21):5547-5558

8. Yang K, Metcalf WW: A new activity for an old enzyme: Escherichia coli bacterial alkaline phosphatase is a phosphite-dependent hydrogenase. Proc Nat Acad Sci 2004, 101(21):7919-7924.

9. Wilson MM, Metcalf WW: Genetic diversity and horizontal transfer of genes involved in oxidation of reduced phosphorus compounds by Alcaligenes faecalis WM2027. Appl Environ Microbiol 2005, 71(1):290-296.

10. Dyhrman ST, Chappell PD, Haley ST, Moffett JW, Orchard ED, Waterbury JB, Webb EA: Phosphonate utilization by the globally important marine diazotroph Trichodesmium. Nature 2006, 439(7072):68-71.
11. Metcalf WW, Wanner BL: Evidence for a fourteen-gene, phnC to phnP locus for phosphonate metabolism in Escherichia coli. Gene 1993, 129(1):27-32.

12. Quinn JP, Peden JMM, Dick RE: Carbon-phosphorus bond cleavage by Gram-positive and Gram-negative soil bacteria. Appl Microbiol Biotechnol 1989, 31:283-287.

13. Schink B, Thiemann V, Laue H, Friedrich MW: Desulfotignum phosphitoxidans sp. nov., a new marine sulfate reducer that oxidizes phosphite to phosphate. Arch Microbiol 2002, 177:381-391.

14. Simeonova DD, Wilson MM, Metcalf WW, Schink B: Identification and heterologous expression of genes involved in anaerobic dissimilatory phosphite oxidation by Desulfotignum phosphitoxidans. J Bacteriol 2010, 192(19):5237-5244.

15. Widdel F, Pfennig N: Studies on dissimilatory sulfate-reducing bacteria that decompose fatty acids. I. Isolation of a new sulfate-reducer enriched with acetate from saline environments-description of Desulfobacter postgatei gen. nov. sp. nov. Arch Microbiol 1981, 129:395-400.

16. Poehlein A, Daniel R, Simeonova DD: Draft genome sequencing of Desulfotignum phosphitoxidans DSM 13687 strain FiPS-3. Genome Announc 2013, 1(3). doi:10.1128/genomeA.00227-13.

17. Sanger F, Nicklen $S$, Coulson AR: DNA sequencing with chain-terminating inhibitors. 1977. Biotechnol 1992, 24:104-108.

18. Staden R, Beal KF, Bonfield JK: The Staden package, 1998. Methods Mol Biol 2000, 132:115-130.

19. Tech M, Merkl R: YACOP: enhanced gene prediction obtained by a combination of existing methods. In Silico Biol 2003, 3(4):441-451.

20. Lagesen K, Hallin P, Rødland EA, Stærfeldt H-H, Rognes T, Ussery DW: RNAmmer: consistent and rapid annotation of ribosomal RNA genes. Nucleic Acids Res 2007, 35(9):3100-3108.

21. Lowe TM, Eddy SR: tRNAscan-SE: a program for improved detection of transfer RNA genes in genomic sequence. Nucleic Acids Res 1997, 25(5):0955-0964.

22. Markowitz VM, Mavromatis K, Ivanova NN, Chen I-MA, Chu K, Kyrpides NC: IMG ER: a system for microbial genome annotation expert review and curation. Bioinformatics 2009, 25(17):2271-2278.

23. Zdobnov EM, Apweiler R: InterProScan - an integration platform for the signature-recognition methods in InterPro. Bioinformatics 2001, 17(9):847-848.

24. Larkin MA, Blackshields G, Brown NP, Chenna R, McGettigan PA, McWilliam $H$, Valentin F, Wallace IM, Wilm A, Lopez R, et al: Clustal W and Clustal X version 2.0. Bioinformatics 2007, 23(21):2947-2948.

25. Bose $M$, Barber R: Prophage Finder: a prophage loci prediction tool for prokaryotic genome sequences. In Silico Biol 2006, 6:0020.

26. Varani A, Siguier P, Gourbeyre E, Charneau V, Chandler M: ISsaga is an ensemble of web-based methods for high throughput identification and semi-automatic annotation of insertion sequences in prokaryotic genomes. Genome Biol 2011, 12(3):R30.

27. Mark Osborn A, Böltner D: When phage, plasmids, and transposons collide: genomic islands, and conjugative- and mobilizable-transposons as a mosaic continuum. Plasmid 2002, 48(3):202-212.

28. Dobrindt U, Hochhut B, Hentschel U, Hacker J: Genomic islands in pathogenic and environmental microorganisms. Nat Rev Micro 2004, 2(5):414-424.

29. Carver T, Thomson N, Bleasby A, Berriman M, Parkhill J: DNAPlotter: circular and linear interactive genome visualization. Bioinformatics 2009, 25(1):119-120.

30. Makarova KS, Haft DH, Barrangou R, Brouns SJJ, Charpentier E, Horvath P, Moineau S, Mojica FJM, Wolf YI, Yakunin AF, et al: Evolution and classification of the CRISPR-Cas systems. Nat Rev Micro 2011, 9(6):467-477.

31. Markowitz VM, Chen I-MA, Palaniappan K, Chu K, Szeto E, Grechkin Y, Ratner A, Jacob B, Huang J, Williams P, et al: IMG: the integrated microbial genomes database and comparative analysis system. Nucleic Acids Res 2012, 40(D1):D115-D122.

32. Fazzio TG, Roth JR: Evidence that the CysG protein catalyzes the first reaction specific to B12 synthesis in Salmonella typhimurium, insertion of cobalt. J Bacteriol 1996, 178(23):6952-6959.

33. Rafter GF: Pyrophosphate metabolism in liver mitochondria. J Biol Chem 1960, 235(8):2475-2477.

34. Rodina EV, Samygina VR, Vorobyeva NN, Stink TS, Kurilova SA, Nazarova TI: Structural and kinetic features of family I inorganic pyrophosphatase from Vibrio cholerae. Biochemistry (Mosc) 2009, 74(7):734-742. 
35. van Veen HW: Phosphate transport in prokaryotes: molecules, mediators and mechanisms. In: Antonie van Leeuwenhoek 1997, 72:299-315.

36. Metcalf WW, Wanner BL: Mutational analysis of an Escherichia coli fourteen-gene operon for phosphonate degradation, using TnphoA' elements. J Bacteriol 1993, 175(11):3430-3442.

37. Borisova SA, Christman HD, Metcalf MEM, Zulkepli NA, Zhang JK, van de Donk WA, Metcalf WW: Genetic and biochemical characterization of a pathway for the degradation of 2-aminoethylphosphonate in Sinorhizobium meliloti 1021. J Biol Chem 2011, 286(25):22283-22290.

38. Jiang W, Metcalf WW, Lee KS, Wanner BL: Molecular cloning, mapping, and regulation of Pho regulon genes for phosphonate breakdown by the phosphonatase pathway of Salmonella typhimurium LT2. J Bacteriol 1995, 177(22):6411-6421.

39. White AK, Metcalf WW: The $h t x$ and ptx operons of Pseudomonas stutzeri WM88 are new members of the Pho regulon. J Bacteriol 2004, 186 (17):5876-5882.

40. Ramos AR, Keller KL, Wall JD, Pereira IAC: The membrane QmoABC complex interacts directly with the dissimilatory adenosine $5^{\prime}$ phosphosulfate reductase in sulfate reducing bacteria. Front Microbiol 2012, 3. doi: 10.3389/fmicb.2012.00137.

41. Mander GJ, Duin EC, Linder D, Stetter KO, Hedderich R: Purification and characterization of a membrane-bound enzyme complex from the sulfate-reducing archaeon Archaeoglobus fulgidus related to heterodisulfide reductase from methanogenic archaea. Eur J Biochem 2002, 269(7):1895-1904.

42. Pereira IAC, Ramos AR, Grein F, Marques MC, Da Silva SM, Venceslau SS: A comparative genomic analysis of energy metabolism in sulfate reducing bacteria and archaea. Front Microbiol 2011, 2:69.

43. Pires RH, Venceslau SS, Morais F, Teixeira M, Xavier AV, Pereira IAC: Characterization of the Desulfovibrio desulfuricans ATCC 27774 DsrMKJOP ComplexA Membrane-Bound Redox Complex Involved in the Sulfate Respiratory Pathway. Biochemistry 2005, 45(1):249-262.

44. Pereira IAC, Ramos AR, Grein F, Marques MC, Da Silva SM, Venceslau SS: A comparative genomic analysis of energy metabolism in sulfate reducing bacteria and archaea. Frontiers in Microbiology 2011, 2. doi:10.3389/ fmicb.2011.00069.

45. Braun $M$, Thöny-Meyer L: Cytochrome $c$ maturation and the physiological role of c-type cytochromes in Vibrio cholerae. J Bacteriol 2005, 187(17):5996-6004

46. Einsle O, Messerschmidt A, Stach P, Bourenkov GP, Bartunik HD, Huber R, Kroneck PMH: Structure of cytochrome c nitrite reductase. Nature 1999 400(6743):476-480

47. Nishimura JS, Griffith MJ: Acetate kinase from Veillonella alcalescens. In: Methods Enzymol 1981, 71:311-316.

48. Bergmeyer HU, Gawehn K, Grassl M: Phosphotransacetylase. In Methoden der enzymatischen Analyse, vol. I. Edited by Bergmeyer UH. Weinheim: Verlag Chemie; 1974:541-542.

49. Glasemacher J, Bock A-K, Schmid R, Schönheit P: Purification and properties of acetyl-CoA synthetase (ADP-forming), an archaeal enzyme of acetate formation and ATP synthesis, from the hyperthermophile Pyrococcus furiosus. Eur J Biochem 1997, 244(2):561-567.

50. Andreesen JR, Ljungdahl LG: Nicotinamide adenine dinucleotide phosphate-dependent formate dehydrogenase from Clostridium thermoaceticum: purification and properties. J Bacterio/ 1974, 120(1):6-14.

51. Höpner T, Knappe J: In Methoden der enzymatischen Analyse, vol. 2. Edited by Bergmeyer HU. Weinheim: Verlag Chemie; 1974:1596.

52. Nakazawa H, Arakaki A, Narita-Yamada S, Yashiro I, Jinno K, Aoki N, Tsuruyama A, Okamura Y, Tanikawa S, Fujita N, et al: Whole genome sequence of Desulfovibrio magneticus strain RS-1 revealed common gene clusters in magnetotactic bacteria. Genome Res 2009, 19(10):1801-1808.

53. Reddy $\mathrm{TL}$, Hendler RW: Reconstitution of Escherichia coli succinoxidase from soluble components. J Biol Chem 1978, 253(21):7972-7979.

54. Chain P, Lamerdin J, Larimer F, Regala W, Lao V, Land M, Hauser L, Hooper A, Klotz M, Norton J, et al: Complete genome sequence of the ammoniaoxidizing bacterium and obligate chemolithoautotroph Nitrosomonas europaea. J Bacteriol 2003, 185(9):2759-2773.

55. Beaumont HJE, Hommes NG, Sayavedra-Soto LA, Arp DJ, Arciero DM, Hooper $A B$, Westerhoff HV, van Spanning RJM: Nitrite reductase of Nitrosomonas europaea is not essential for production of gaseous nitrogen oxides and confers tolerance to nitrite. J Bacteriol 2002, 184(9):2557-2560.
56. Andrews SC, Berks BC, McClay J, Ambler A, Quail MA, Golby P, Guest JR: A 12-cistron Escherichia coli operon (hyf) encoding a putative protontranslocating formate hydrogenlyase system. Microbiology 1997, 143(11):3633-3647.

57. Pereira P, He Q, Valente FA, Xavier A, Zhou J, Pereira IC, Louro R: Energy metabolism in Desulfovibrio vulgaris Hildenborough: insights from transcriptome analysis. Antonie van Leeuwenhoek 2008, 93(4):347-362

58. Brüggemann $H$, Bäumer S, Fricke WF, Wiezer A, Liesegang $H$, Decker I, Herzberg C, Martínez-Arias R, Merkl R, Henne A, et al: The genome sequence of Clostridium tetani, the causative agent of tetanus disease. Proc Natl Acad of Sci 2003, 100(3):1316-1321.

59. Kumagai H, Fujiwara T, Matsubara H, Saeki K: Membrane localization, topology, and mutual stabilization of the $\operatorname{nfABC}$ gene products in Rhodobacter capsulatus and implications for a new family of energycoupling NADH oxidoreductases. Biochemistry 1997, 36(18):5509-5521.

60. Biegel E, Schmidt S, Gonzalez JM, Müller V: Biochemistry, evolution and physiological function of the Rnf complex, a novel ion-motive electron transport complex in prokaryotes. Cell Mol Life Sci 2011, 68:613-634.

61. Jouanneau $Y$, Jeong H-S, Hugo N, Meyer C, Willison JC: Overexpression in Escherichia coli of the rnf genes from Rhodobacter capsulatus. Eur $J$ Biochem 1998, 251(1-2):54-64.

62. Poehlein $A$, Schmidt $S$, Kaster $A-K$, Goenrich $M$, Vollmers J, Thürmer $A$, Bertsch J, Schuchmann K, Voigt B, Hecker $M$, et al: An ancient pathway combining carbon dioxide fixation with the generation and utilization of a sodium ion gradient for ATP synthesis. PLOS ONE 2012, 7(3):e33439.

63. Hayashi $\mathrm{M}$, Unemoto $\mathrm{T}$ : The $\mathrm{Na}+-$ translocating $\mathrm{NADH}$-quinone reductase of marine and moderately halophilic bacteria. In Respiration in Archaea and Bacteria. Edited by Zannoni D. New York, United States: Springer-Verlag New York; 2004:155-174.

doi:10.1186/1471-2164-14-753

Cite this article as: Poehlein et al:: Life based on phosphite: a genomeguided analysis of Desulfotignum phosphitoxidans. BMC Genomics $201314: 753$.

\section{Submit your next manuscript to BioMed Central and take full advantage of:}

- Convenient online submission

- Thorough peer review

- No space constraints or color figure charges

- Immediate publication on acceptance

- Inclusion in PubMed, CAS, Scopus and Google Scholar

- Research which is freely available for redistribution
C) Biomed Central 